\title{
EFFECT OF XENOGRAFT ON ALVEOLAR BONE HEALING FOLLOWING REMOVAL OF IMPACTED THIRD MOLAR: A RANDOMIZED CONTROLLED CLINICAL TRIAL
}

\author{
Inass Abdel Rahman AbuElmagd* and Sara Soliman **
}

\begin{abstract}
Objectives: This study aimed to evaluate the clinical and radiographic outcomes of the xenograft in the extraction socket following the surgical removal of impacted mandibular third molar.

Patients \& Methods: The study was conducted on sixty patients with asymptomatic bilateral impacted mandibular third molars. The molar on one side was extracted and xenograft (Bio-oss ${ }^{\circledR}$ Geistlich Pharma AG, Switzerland) was placed in the extraction socket (study side); the molar on the other side was extracted two weeks later and the extraction socket was left to heal naturally (control side).
\end{abstract}

Results: Pain, maximal incisal opening and swelling were significantly improved in the study group when compared to the control group. Values of bone density were higher in the study group throughout the follow-up period.

Conclusion: Incorporation of xenograft material plays an important role in increasing the alveolar bone density, enhancement of postoperative pain, swelling, range of mouth opening and gives better wound healing.

KEY WORDS: third molar, pain, trismus, swelling, Bio-Oss graft

\section{INTRODUCTION}

Removal of impacted lower third molar is considered as the most common surgical procedure carried out in the oral and maxillofacial Clinics. ${ }^{(1)}$ The surgical removal of the impacted mandibular third molar is usually associated with pain, swelling and inability to open the mouth. Those symptoms reach the maximum intensity between the third to fifth hours postoperatively for the pain and 24 to 48 hours postoperatively for the swelling and then, they gradually diminished until the $7^{\text {th }}$ day postoperatively. ${ }^{(2,3)}$

* Lecturer of Oral Radiology, Faculty of Dentistry, Fayoum University

** Lecturer of Oral \& Maxillofacial Surgery, Faculty of Dentistry, Pharos University in Alexandria (PUA) 
In addition to those symptoms, there is a considerable risk of developing periodontal defects on the distal aspect of mandibular second molars after mandibular third molar removal. Kan and his colleagues in $2002^{(4)}$ published a study that observed the periodontal conditions distal to mandibular second molars 6-36 months after routine surgical extraction of adjacent impacted third molars. They stated that $67 \%$ of patients exhibiting Periodontal Pocket Depth (PPD) >or $=5 \mathrm{~mm}$ and $23 \%$ exhibiting PPD $>$ or $=7 \mathrm{~mm}$ and they observed a mean recession of $0.8+/-1.0 \mathrm{~mm}$ along the distal aspect of the second molar.

Once the periodontal defect and intrabony defect developed, they became difficult to treat through the traditional root planning, or simple local curettage and debridement ${ }^{(5)}$ Therefore, it is beneficial to take into consideration that bone grafting of the resultant defects immediately following the surgical removal of impacted mandibular third molars as this will maintain the periodontal health through preserving the alveolar bone height. ${ }^{(4)}$ Various studies with different materials have been used for prevention and management of these common complications. ${ }^{(6-8)}$

Among these materials used to fill the socket of the mandibular third molar was Bio-Oss ${ }^{\circledR}$ xenograft material which presented in the market as a resorbable an organic porous bovine hydroxyapatite scaffold. The Bio-Oss ${ }^{\circledR}$ xenograft material had been used to repair the periodontal and maxillofacial osseous defects. It is degraded slowly in the body which considered as advantage as it reduces the bone loss within the defect that results from the remodeling after the augmentation procedures. ${ }^{(9-12)}$

Moreover, many methods have been used to stimulate bone healing either with chemical or physical stimuli. The use of physical stimuli and more recently is ozone therapy. ${ }^{(13,14)}$

Scientific evidence pertaining to management of impacted third molar removal and post-extraction healing has been previously summarized in different reviews, mainly being limited to qualitative evaluation. ${ }^{(15-19)}$ Therefore, the aim of this study was to evaluate the clinical and radiographic outcomes of Bio-Oss ${ }^{\circledR}$ xenograft material on extraction socket following the surgical extraction of impacted mandibular third molar.

\section{PATIENTS AND METHODS}

\section{Participants}

Sixty healthy patients require removal of bilateral impacted mandibular third molar participated in this study. Their age ranged from 18 to 35 years. The participants were recruited from Outpatient clinics of Oral and Maxillofacial Surgery Department, Faculty of Dentistry, Fayoum University.

Patient selection was based on certain inclusion and exclusion criteria. The inclusion criteria include age $>18$ years, with no systemic disease(s), and bilateral impacted mandibular third molar class II position B on Pell- Gregory classification. On the other hand, the exclusion criteria include any patients that had any contraindication to graft therapy, local infection, tobacco use, oral contraceptive, pregnancy, lactation in addition to patients who had taken analgesics or anti-inflammatories for 1 week prior to enrollment in the study.

Completed medical and dental history was taken for all patients and the position of the impacted teeth was evaluated by panoramic films. Patients were fully informed about the treatment procedures, follow-up examinations and complications of surgical procedures. Informed consent was obtained from each patient prior to participation in the study. The study was approved by the ethics committee of Faculty of Dentistry, Fayoum University.

\section{Study Design}

The study was carried out as a randomized controlled clinical trial, split mouth design. 
Randomly, by the use of predefined computergenerated randomization table, molar on one side was allocated to receive xenograft (Bio-oss ${ }^{\circledR}$ Geistlich Pharma AG, Switzerland) in the extraction socket (study side). The molar on the other side was extracted 2 weeks later and left to heal naturally (control group). Patients were blinded to which side was grafted and which was control.

All Patients were subjected to a standardized surgical protocol by the same surgeon and another operator carried out the postoperative measurement.

\section{Surgical procedures}

All surgeries were performed under complete aseptic conditions. Before surgery, the patient's mouth was rinsed with a chlorhexidine digluconate solution $0.2 \%$ for 2 minutes. Surgery was carried out under local anesthesia consisting of $2 \%$ lidocaine hydrochloride with 1: 80,000 adrenaline (Lignospan Special, Septodont, UK). An extended buccal mucoperiosteal flap was elevated providing access to the impacted third molar. The bone guttering was achieved under continuous sterile saline solution irrigation. When necessary, sectioning of crown and roots was performed with a fissure bur. After tooth extraction, the alveolus was inspected, curetted, and irrigated with $0.9 \%$ sterile saline solution. Thereafter Bio-oss ${ }^{\circledR}$ was mixed with saline only (Study side) and carefully packed in the extraction socket or left to heal naturally without grafting (control side) and carefully packed in the extraction socket. The threesided mucoperiosteal flap was repositioned and sutured with 3-0 black silk suture.

Postoperatively, the patients were instructed to apply ice bags $20 \mathrm{~min} /$ hour for the next 6 hours to the surgical side, eat soft cold diet by the aid of a straw and to avoid hot diet and fluid on the day of surgery. Postoperative antibiotic of $875 \mathrm{mg}$ Amoxicillin and $125 \mathrm{mg}$ Clavulanic acid (Augmentin $1 \mathrm{gm}$, Smithline Beecham Pharmaceutical Co., Bentford, England) twice a day for five days post-operatively and non-steroidal anti- inflammatory drug in the form of diclofenac potassium $50 \mathrm{mg}$ (Cataflam 50mg tablets, Novartis Pharma AG, Basle, Switzerland) three times daily and chlorhexidine gluconate solution (Hexitol mouth wash, the Arab Drug Co., Cairo, Egypt) as a mouth rinse for a period of five days were prescribed to the patients. Sutures were removed after 7 days postoperatively.

\section{Postoperative Evaluation}

All the patients were evaluated on the $1^{\text {st }}, 3^{\text {rd }}$, $5^{\text {th }}$ and $7^{\text {th }}$ postoperative days for pain, preoperative and postoperative mouth opening, and degree of postoperative swelling. Also the bone density within the extraction socket was evaluated.

Pain was assessed using a visual analogue scale (VAS) of 10 units in combination with a graphic rating scale. ${ }^{(20)}$ On the VAS, the left most end represented the absence of pain (score 0 ) and the right most end indicated the most severe pain (score 10). Preoperative and postoperative mouth opening was evaluated by measurement of the maximal distance between the cutting edge of the right maxillary and right mandibular central incisors with a caliper ${ }^{21)}$. The degree of postoperative swelling was measured $(\mathrm{cm})$ using a tape measure, from the tragus to the corner of the mouth. ${ }^{(22)}$ The preoperative measurements were considered as the baseline values and the extent of the swelling was determined on postoperative days $1,3,5$, and 7 . The difference between each postoperative evaluation and the baseline value indicated the facial swelling for that day.

The bone density within the extraction socket was measured using software of digora (DIGORA ${ }^{\circledR}$ for Windows 2.7 software, The Dental Imaging Company Ltd Digora, USA.). For this purpose, Patients were subjected to panoramic imaging immediate, $1^{\text {st }}, 3^{\text {rd }}$ and $6^{\text {th }}$ month postoperatively.

During examination of the patients, each patient was precisely aligned at the X-ray machine 
using laser alignment beams, hence guaranteeing positioning all the patients at the same position.

\section{Statistical analysis of the data}

Data were fed to the computer and analyzed using IBM SPSS software package version 20.0. Qualitative data were described using number and percent. Student t-test was used to compare two groups for normally distributed quantitative variables while Paired t-test was assessed for comparison between different periods. For abnormally distributed quantitative variables Mann Whitney test was used for comparing each two groups, while Wilcoxon signed ranks test was assessed for comparison between different periods. Significance of the obtained results was judged at the $5 \%$ level.

\section{RESULTS}

This study was conducted on sixty (60) patients with bilateral impacted mandibular third molar. Twenty-nine patients were males (48.3\%) and thirty-one were females $(51.7 \%)$ their mean \pm SD age was $23.33 \pm 4.70$ (range 18-35).

The surgical procedure was performed for both sides without any complication in all patients. The mean operation time (from the start of the incision to the end of suturing) was $22 \pm 9$ min for the study side while in the control side, the mean operation time was $23 \pm 11 \min (\mathrm{p}<0.001)$.

The patients were evaluated and followed up for pain, swelling, maximum mouth opening for intervals of $1^{\text {st }}, 3^{\text {rd }}, 5^{\text {th }}$ and $7^{\text {th }}$ day postoperatively. In addition to those clinical parameters, the patients were also evaluated and followed up radiographically for bone density on intervals of $1^{\text {st }}$, $3^{\text {rd }}$ and $6^{\text {th }}$ months postoperatively.

\section{Pain}

The pain scores recorded their highest value on the first day postoperative in both groups and it drops significantly by the $7^{\text {th }}$ day postoperative. The pain score recorded a significantly lower value on the study side than that of the control side at all intervals of evaluation $(p<0.001)$. (Table1)

\section{Swelling}

The postoperative swelling occurred on both control and study sides. The study side showed significantly less facial swelling than the control side all over the follow up period (Table 2). Also the results showed that in the study side the swelling resolved on the $7^{\text {th }}$ day postoperative while in the control side the patients still had residual swelling that did not resolved completely by the end of the first postsurgical week.

\section{Maximum interincisal opening}

The Maximum interincisal opening was restricted on both sides. Maximum interincisal opening showed lowest value in the $1^{\text {st }}$ day postoperative in both groups and improved significantly by the $7^{\text {th }}$ day postoperative. When comparing both sides, trismus on the study side was significantly less than that on the control side. (Table3)

\section{Bone Density}

Within the study side, the mean bone density value increased continuously through the $1^{\text {st }}, 3^{\text {rd }}$ and $6^{\text {th }}$ months postoperative. The increase in bone density was statistically significant throughout the different follow up periods. In the control side, the mean bone density value was also increased throughout the follow up period. The improvement in the bone density was greater in the study side than in the control side. The difference between two sides showed a statistically significant relation ( $\mathrm{P}$ $<0.001$ ) (Table 4). 
TABLE (1): Comparison between the two studied groups according to pain score

\begin{tabular}{|c|c|c|c|c|}
\hline & \multicolumn{4}{|c|}{ Pain Score } \\
\hline & $1^{\text {st }}$ Day & $3^{\text {rd Day }}$ & $5^{\text {th }}$ Day & $7^{\text {th }}$ Day \\
\hline \multicolumn{5}{|l|}{ Study $(n=60)$} \\
\hline Mean \pm SD & $5.05 \pm 0.87$ & $2.92 \pm 0.87$ & $1.53 \pm 0.75$ & $0.27 \pm 0.45$ \\
\hline $\mathbf{p}_{1}$ & & $<0.001^{*}$ & $<0.001^{*}$ & $<0.001^{*}$ \\
\hline \multicolumn{5}{|l|}{ Control $(n=60)$} \\
\hline Mean \pm SD & $6.80 \pm 0.73$ & $4.55 \pm 0.72$ & $2.22 \pm 0.67$ & $0.88 \pm 0.49$ \\
\hline$p_{1}$ & & $<0.001^{*}$ & $<0.001^{*}$ & $<0.001^{*}$ \\
\hline $\mathbf{p}_{2}$ & $<0.001^{*}$ & $<0.001^{*}$ & $<0.001^{*}$ & $<0.001^{*}$ \\
\hline
\end{tabular}

$p_{1}$ : p value for Wilcoxon signed ranks test for comparing between $1^{\text {st }}$ day and each other periods

$p_{2}: p$ value for Mann Whitney test for comparing between the two studied groups

*: Statistically significant at $p \leq 0.05$

TABLE (2): Comparison between the two studied groups according to swelling

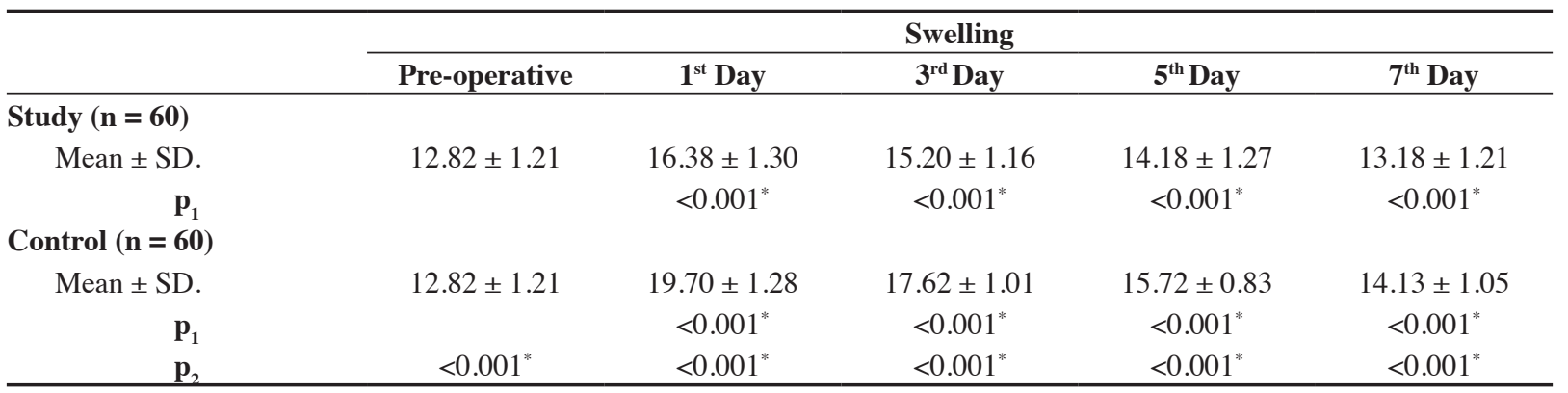

$p_{1}: p$ value for Paired t-test for comparing between Preoperative and each other periods

$p_{2}$ : p value for Student t-test for comparing between the two studied groups

*: Statistically significant at $p \leq 0.05$

TABLE (3): Comparison between the two studied groups according to maximal incisal opening

\begin{tabular}{|c|c|c|c|c|c|}
\hline & \multicolumn{5}{|c|}{ Mouth opening } \\
\hline & Pre-operative & $1^{\text {st }}$ Day & $3^{\text {rd }}$ Day & $5^{\text {th }}$ Day & $7^{\text {th }}$ Day \\
\hline \multicolumn{6}{|l|}{ Study $(n=60)$} \\
\hline Mean \pm SD & $41.58 \pm 1.24$ & $31.12 \pm 1.42$ & $34.78 \pm 1.54$ & $38.15 \pm 1.44$ & $41.58 \pm 1.24$ \\
\hline \multirow{2}{*}{\multicolumn{6}{|c|}{$\begin{aligned} & p_{1} \\
& \text { Control }(n=60)\end{aligned}$}} \\
\hline & & & & & \\
\hline Mean \pm SD & $41.58 \pm 1.24$ & $25.73 \pm 1.81$ & $31.20 \pm 1.68$ & $34.82 \pm 1.72$ & $38.33 \pm 1.42$ \\
\hline$p_{1}$ & & $<0.001^{*}$ & $<0.001^{*}$ & $<0.001^{*}$ & $<0.001^{*}$ \\
\hline $\mathbf{p}_{2}$ & $<0.001^{*}$ & $<0.001^{*}$ & $<0.001^{*}$ & $<0.001^{*}$ & $<0.001^{*}$ \\
\hline
\end{tabular}

$p_{I}: p$ value for Paired t-test for comparing between Preoperative and each other periods

$p_{2}: p$ value for Student t-test for comparing between the two studied groups

*: Statistically significant at $p \leq 0.05$ 
TABLE (4): Comparison between the two studied groups according to bone density

\begin{tabular}{|c|c|c|c|}
\hline & \multicolumn{3}{|c|}{ Bone density } \\
\hline & $1^{\text {st }}$ Month & $3^{\text {rd }}$ Months & $6^{\text {th }}$ Months \\
\hline \multicolumn{4}{|l|}{ Study $(n=60)$} \\
\hline Mean \pm SD & $659.57 \pm 25.70$ & $782.47 \pm 25.04$ & $914.58 \pm 41.59$ \\
\hline $\mathbf{p}$ & & $<0.001^{*}$ & $<0.001^{*}$ \\
\hline \multicolumn{4}{|l|}{ Control $(n=60)$} \\
\hline Mean \pm SD & $539.0 \pm 49.87$ & $647.22 \pm 47.32$ & $795.15 \pm 34.37$ \\
\hline $\mathbf{p}$ & & $<0.001^{*}$ & $<0.001^{*}$ \\
\hline $\mathbf{p}$ & $<0.001^{*}$ & $<0.001^{*}$ & $<0.001^{*}$ \\
\hline
\end{tabular}

$p_{1}: p$ value for Paired t-test for comparing between Preoperative and each other periods

$p_{2}: p$ value for Student t-test for comparing between the two studied groups

*: Statistically significant at $p \leq 0.05$

\section{DISCUSSION}

The removal of the impacted mandibular third molar is usually associated with pain, swelling and trismus as postoperative sequelae following surgery. Moreover, there is a risk of developing a periodontal defect on the distal surface of mandibular second molar. All of those symptoms affect the quality of the patient's life after the surgical procedure. ${ }^{(3-5,21)}$

Many methods had been used to decrease the postoperative symptoms and improve the healing of the surgical sites. The present study aimed to investigate the effect Xenograft on the bone healing after surgical removal of mandibular third molar.

Management of impacted third molars had a relevant challenge for the clinician as surgical removal of wisdom teeth has been associated with the risk of having persistent or developing a periodontal defect at the distal aspect of the mandibular second molar $^{(9-13)}$

In order to reduce the risk of periodontal defects developments, different treatment strategies have been proposed such as adjunctive systematic debridement of second molar distal root surface, specific access flap designs, soft tissues suturing, regenerative procedures and bone grafting techniques for their potential benefits in periodontal healing distally to second molar compared to conventional third extractions ${ }^{(15-19)}$

In the current study, the xenograft has been used to improve the bone healing of the socket in addition to reduce the postoperative symptoms such as the pain, trismus and swelling.

Split- mouth design was chosen to conduct the current study to avoid any possible bias in allocating individuals in control and study groups. The current study was conducted on patients with bilateral third molar which are symmetrical in position and degree of difficulty. Furthermore, single surgeon preformed all surgical procedures and another surgeon collect the data in the follow-up period in order to remove any possible differences that could resulted from different surgeon's skills.

In the present study, the pain was evaluated using the visual analog scale on intervals of $1^{\text {st }}, 3^{\text {rd }}, 5^{\text {th }}$ and $7^{\text {th }}$ day postoperative. The patients experience significantly less pains at the study side than that on the control side. These results were in agreement with the results of Throndson RR et al (2002) (22) who conducted a study to evaluate the effect of the xenograft therapy on pain after the third molar surgery. 
In addition to the effect of grafting on pain, the trismus and swelling also affected by the addition of the graft material to the extraction socket. The results of this current study showed a positive effect of xenograft on the trismus which decreased significantly in the study side that received graft material. Also the facial swelling had reduced and resolved more rapidly in the study side that received Bio-oss graft when compared to the control side. Those results differ from the results that were presented by Throndson RR et al (2002) ${ }^{(22)}$ which showed that the graft material had no effect on swelling and trismus. This could be explained by the difference of the method by which the graft applied as the authors applied a membrane to the extraction socket. In the current study, the graft was applied alone with no membrane which ensure longer exposure of the surgical field to the effect of oral flora. ${ }^{(22)}$

Grafting the extraction socket with Biooss Xenograft had been tested widely in the literature. ${ }^{(9-11)}$ Regarding the bone density within the surgical site, the results of present study showed a statistically significant improvement in the bone density in the ozonated side. Those results were in agreement with Hassan et al ${ }^{(23)}$ who studied the effect of an organic xenograft on bone healing in extraction socket of the third molars and concluded that grafting had a positive effect on the bone healing more than non-grafted sites.

In contrast, in a recent study performed in 2017 by Zhou et al ${ }^{(25)}$ who he microenvironment changes in the sockets substituted with bovine-derived xenografts during the early healing period. They concluded that the bovine-derived xenografts may interfere with the healing process of the extraction socket in the early healing stage. Bone formation of the extraction socket was delayed after grafting with bone substitute.

Another study by Heberer $\mathrm{S}$ et al (2011) investigated bone formation in human extraction sockets augmented with Bio-Oss Collagen after a 12-week healing period was quantified and compared to bone formation in un-augmented extraction sockets. The study found that bone formation in BioOss Collagen-grafted human extraction sockets was lower than bone formation in un-grafted sockets Bone formation occurred in all specimens with varying degrees of maturation independent of the grafting material and was initiated from the apical region.

\section{CONCLUSIONS}

Within the limitations of the current study, it may be concluded that the incorporation of the graft material plays a significant role in; the increase of alveolar bone density, the decrease of postoperative pain and swelling, the improvement of maximal mouth opening and the enhancement of wound healing.

\section{Conflicts of Interests}

The authors declare that there are no competing interests regarding the publication of this paper.

\section{REFERENCES}

1- Ahmed A, Mohamed F, Hattab K. Surgical extraction of impacted mandibular third molars: postoperative complications and their risk factors. JMJ 2009; 9:272-275

2- Lago ML, Dinitz FM, Serna RC, Gude-Sampedro F, Gándara Rey JM, García-García A. Relationships between surgical difficulty and postoperative pain in lower third molar extractions. J Oral Maxillofac Surg 2007; 65: 979-983.

3- López-Ramírez M, Vílchez-Pérez MA, Gargallo-Albiol J, Arnabat- Domínguez J, Gay-Escoda C. Efficacy of low-level laser therapy in the management of pain, facial swelling, and postoperative trismus after a lower third molar extraction. A preliminary study. Lasers Med Sci 2012; 27:559-566

4- Kan KW, Liu JK, Lo EC, Corbet EF, Leung WK. Residual periodontal defects distal to the mandibular second molar 6-36 months after impacted third molar extraction. J Clin Periodontol. 2002; 29:1004-11. 
5- Coceancig PLG. Alveolar bone grafts distal to the lower second molar. J Maxillofac Oral Surg 2009; 8:22-6.

6- $\quad$ Peng KY, Tseng YC, Shen EC, Chiu SC, Fu E, Huang YW. Mandibular second molar periodontal status after third molar extraction. J Periodontol 2001; 72:1647-1651

7- Dodson TB. Management of mandibular third molar extraction sites to prevent periodontal defects. J Oral Maxillofac Surg 2004; 62:1213-1224

8- Sammartino G, Tia M, Bucci T, Wang HL. Prevention of mandibular third molar extraction-associated periodontal defects: a comparative study. J Periodontol 2009; 80:389396.

9- Carmagnola, D., Adriaens, P. \& Berglundh, T. Healing of human extraction sockets filled with Bio-oss. Clinical Oral Implants Research 2003;14: 137-143

10- Stavropoulos, A., Kostopoulos, L., Nyengaard, JR. \& Karring, T. Fate of bone formed by guided tissue regeneration with or without grafting of BioOsss or Biograns . An experimental study in the rat. Journal of Clinical Periodontology 2004; 31: 30-39.

11- Rumpel, E., Wolf, E., Kauschke, E., Bienengra“ber, V., Bayerlein, T., Gedrange, T. \& Proff, P. The biodegradation of hydroxyapatite bone graft substitutes in vivo. Folia Morphol (Warsz) 2006; 65: 43-48.

12- Skoglund, A., Hising, P. \& Young, C. A clinical and histologic examination in humans of the osseous response to implanted natural bone mineral. International Journal of Oral and Maxillofacial Implants 1997; 12: 194-199.

13- Negata MJ, Santinoni CS, Pola NM, et al. Bone marrow aspirate combined with low level laser therapy: a new therapeutic approach to enhance bone healing. J Photochem Photobiol B 2013; 5:6-13.

14- Ozdemir H, Toker H, Balcı H, Ozer H. Effect of ozone therapy on autogenous bone graft healing in calvarial defects: a histologic and histometric study in rats. J Periodontal Res 2013; 48:722-6.

15- Ramírez V, Marró P, López R. Effect of mechanical debridement on distal periodontal aspects of second molars after the extraction of third molars: a systematic review. J Periodontol. 2012; 83:595-601.
16- Haug RH, Abdul-Majid J, Blakey GH, et al. Evidencedbased decision making: the third molar. Dent Clin North Am. 2009; 53:77-96.

17- Moher D, Liberati A, Tetzlaff J, et al. Preferred reporting items for systematic reviews and meta-analyses: the PRISMA statement. J Clin Epidemiol. 2009; 62:10061012 .

18- Grossi GB, Maiorana C, Garramone RA, Borgonovo A, Creminelli L, Santoro F. Assessing postoperative discomfort after third molar surgery: a prospective study. J Oral Maxillofac Surg 2007; 65:901-17.

19- Markovic A, Todorovic L. Effectiveness of dexamethasone and low-power laser in minimizing oedema after third molar surgery: a clinical trial. Int $\mathrm{J}$ Oral Maxillofac Surg2007; 36:226-9.

20- Schultze-Mosgau S, Schmelzeisen R, Fro-lich JC, Schmele H. Use of ibuprofen and methylprednisolone for the prevention of pain and swelling after removal of impacted third molars. J Oral Maxillofac Surg 1995; 53:2-7.

21- Deepti C, Rehan HS, Mehra P. Changes in quality of life after surgical removal of impacted mandibular third molar teeth. J Maxillofac Oral Surg. 2009; 8:257-60.

22- Throndson RR, Sexton SB. Grafting mandibular third molar extraction sites: A comparison of bioactive glass to a nongrafted site. Oral Surgery, Oral Med Oral Pathol Oral Radiol Endodontology. 2002; 94:413-419.

23- Hassan KS, Marei HF, Alagl AS. Does grafting of third molar extraction sockets enhance periodontal measures in 30- to 35-year-old patients? J Oral Maxillofac Surg. 2012;70:757-64.

24- Zhou F, Zheng X, Xie M, Mo A, Wu H. Radiographic and Histological Evaluation of the Healing of Extraction Sockets Filled With Bovine-Derived Xenograft: An Experimental Study in Rats. Implant Dent. 2017; 26:400-404.

25- Heberer S, Al-Chawaf B, Jablonski C, Nelson JJ, Lage $\mathrm{H}$, Nelson K. Healing of ungrafted and grafted extraction sockets after 12 weeks: a prospective clinical study. Int J Oral Maxillofac Implants. 2011;26:385-92. 